\title{
Nodular Goiter:
}

\section{Cautious Indications for Surgery}

\author{
Roland Gärtner
}

Editorial to accompany the article "The Surgical Treatment of Bilateral Benign Nodular Goiter" by Nada Rayes et al. in this issue of Deutsches Ärzteblatt International

\footnotetext{
Medical Clinic IV,

$\mathbf{R}$ oughly 100000 patients undergo thyroid surgery in Germany every year. Total thyroidectomy is often performed for benign nodular goiter to prevent recurrence. In this issue of Deutsches Ärzteblatt International, N. Rayes and coauthors summarize the available data on surgery for bilateral benign nodular goiter and conclude that alternative treatments such as the Dunhill procedure still have a role to play alongside total thyroidectomy, as they are sufficiently radical but have markedly fewer complications (1).

\section{Total thyroidectomy or a subtotal procedure}

In recent years, there has been an interdisciplinary, at times contentious debate on whether benign nodular goiter should be treated with total thyroidectomy or with a subtotal procedure. The main arguments for total thyroidectomy are, first, that no further surgery will be needed in case histology reveals an incidental microcarcinoma; and, second, that total thyroidectomy eliminates the risk of recurrent goiter and with it the potential need for reoperation, which has much more frequent postoperative complications than initial surgery (2).

An important preliminary question in this debate is whether, and when, surgery is truly indicated for benign nodular goiter. $20-30 \%$ of the German population have benign nodular goiter (3), and most of these persons remain asymptomatic as long as their thyroid function is normal, because thyroid nodules generally enlarge slowly without being noticed by the patient. The number of thyroid operations in Germany has recently declined from about 120000 to about 90000 per year, but this is still 4-6 times the annual rate of surgery in other countries. Now as in the past, most thyroid operations in Germany are for benign nodular goiter (4). About half of these operations are partial thyroidectomies, and about $40 \%$ are total thyroidectomies (2).

The indications for goiter surgery should be based on the recommendations of the current guidelines from Germany and abroad $(5,6)$. In these guidelines, it is clearly stated that surgery for a confirmed benign nodular goiter is indicated only if the patient has local symptoms or functional disturbances for which there is no other treatment. The recommended management of incidentally discovered nodules consists of an ultrasonographic study together with

- scintigraphy for nodules larger than $1 \mathrm{~cm}$, and

- fine-needle puncture for functionally inactive nodules.
If a cancerous lesion has been excluded, thyroidectomy is not necessary (6). The consistent application of this principle would vastly reduce the overall number of operations on patients with benign nodular goiter. The same holds for recurrences of benign nodular goiter; not every benign nodule needs to be operated on, but rather only those that cause local compressive symptoms or that are suspected to be malignant or have been confirmed as such by biopsy (5).

\section{Predominantly papillary microcarcinoma}

Surgery is often justified by the argument that any nodule might be harboring a cancerous lesion. When this argument is made, surgery tends to be performed without any precise diagnostic evaluation beforehand (4). A further argument one sometimes hears is that a benign nodule might become malignant later on. There is no evidence whatever for this assertion.

In one of the largest studies on this topic, 134 patients with cytologically confirmed benign nodules were observed for a further ten years. Approximately one-third of the nodules enlarged over time, and only one of these was a papillary carcinoma (7). It can be presumed that the fine-needle puncture was falsely negative in this particular case, as the growth of a nodule is not a sign of malignancy (8).

A significant rise in the frequency of thyroid carcinoma has been reported in nearly all countries where the matter has been studied, but this is largely accounted for by papillary microcarcinomas, which are now more commonly discovered incidentally because of improved diagnostic imaging (9). They are also being discovered more commonly as incidental findings in surgical specimens. In earlier years, pathologists usually histologically examined only two blocks of surgical material; nowadays, up to nine blocks are studied, so that very small, subclinical papillary microcarcinomas are more likely be found (10). This more thorough histological examination was widely adopted because of the findings of a fairly old Finnish study of consecutive autopsies, in which more than 100 adult thyroids were histologically studied in sections spaced $2-3 \mathrm{~mm}$ apart. $35 \%$ were found to contain papillary microcarcinomas (11).

\section{Relatively good prognosis}

The prognosis of incidental papillary microcarcinoma of the thyroid is just as good without total thyroidectomy as it is in patients who undergo total thyroidectomy 
because of a preoperatively diagnosed carcinoma, as a Danish study showed (12). Over 15 years of follow-up, $98.5 \%$ of patients in both groups were free of recurrences.

Thus, the greater postoperative morbidity of total thyroidectomy must be weighed against the chance of recurrence and of missing a papillary microcarcinoma when a subtotal procedure is performed.

As for complications, which are generally transient but sometimes permanent (including recurrent laryngeal nerve palsy and hypoparathyroidism), the morbidity of total thyroidectomy for benign thyroid disease is dauntingly high.

Neuromonitoring is now recommended as the method of choice for preventing recurrent laryngeal nerve palsy. The frequency of a permanent complication of this type is less than $1 \%$ in specialized centers, but markedly higher in routine clinical practice (2).

After total thyroidectomy, $10-20 \%$ of patients have transient hypoparathyroidism and 3-5\% have permanent hypoparathyroidism $(2,13)$. These rates are markedly lower after subtotal thyroidectomy or a Dunhill procedure ( $0.8 \%$ and $1.4 \%$, respectively) (2).

\section{Individualized treatment}

One can only conclude that a substantial degree of postoperative morbidity results from the large volume of thyroid surgery now being performed in Germany. Patients should be selected for surgery with great care, and the type of operation to be performed should be chosen on an individual basis, with consideration not just of the patient's underlying disease, but also of the surgeon's experience. Because patients with bilateral nodules and a positive family history may have a genetic predisposition, they should undergo total thyroidectomy in a specialized center, rather than a Dunhill procedure (2). On the other hand, if a histological finding of papillary microcarcinoma is obtained postoperatively after an operation that was not a total thyroidectomy, a second operation to complete the resection of the thyroid is not obligatory in all cases $(2,12)$.

L-thyroxine supplementation is adequate treatment after total thyroidectomy, but a combination of Lthyroxine with iodide is always indicated after subtotal procedures. No sufficiently valid clinical trials on this topic have been performed to date; even so, epidemiological and experimental clinical studies have clearly shown that nodular goiter is due to iodine deficiency - it is not caused by elevated TSH alone, but by a lack of iodine (14). It follows that combined iodide and thyroid hormone supplementation is indicated. Clinical trials on this topic are urgently needed. Combined supplementation might markedly lower the re- currence rate of nodular goiter after subtotal resection, which has been reported to be as high as $10 \%(2)$.

\section{Conflict of interest statement}

The author states that he has no conflict of interest.

Translated from the original German by Ethan Taub, M.D.

\section{REFERENCES}

1. Rayes N, Seehofer D, Neuhaus $P$ : The surgical treatment of bilateral benign nodular goiter-balancing invasiveness with complications. Dtsch Arztebl Int 2014; 111(10): 171-8.

2. Musholt TJ: Totale Thyreoidektomie bei Knotenstruma. Chirurg 2010: 81: 603-11.

3. Völzke H, Ludemann J, Robinson DM, et al.: The prevalence of undiagnosed thyroid disorders in a previously iodine-deficient area. Thyroid 2003; 13: 803-10.

4. Wienhold R, Scholz M, Adler JR, et al.: The management of thyroid nodules. A retrospective analysis of health insurance data. Dtsch Arztebl Int 2013; 110: 827-34.

5. Musholt TJ, Clerici T, Dralle H, et al.: German Association of Endocrine Surgeaons practice guidelines for surgical treatment of benign thyroid disease. Langenbecks Arch Surg 2011; 396: 639-49.

6. Gharib H, Papini E, Paschke R, et al.: AACE/AME/ETA Task Force on Thyroid Nodules. American Association of Clinical Endocrinologists, Associazione Medici Endocrinologi, and European Thyroid Association medical guidelines for clinical practice for the diagnosis and management of thyroid nodules: executive summary of recommendations. J Endocrinol Invest 2010; 33: 51-6.

7. Kuma K, Matsuzuka F, Yokozawa T, et al.: Fate of untreated benigne thyroid nodules: Results of long-term follow-up. World J Surg 1994; 18: 495-9.

8. Asanuma K, Kobayashi S, Shingu K, et al.: The rate of tumour growth does not distinguish between malignant and benigne thyroid nodules. Eur J Surg 2001; 167: 102-5.

9. Brito JP, Davies L, Zeballo-Palacios C, et al.: Papillary lesions of indolent course: reducing the overdiagnosis of indolent papillary thyroid cancer and unnecessary treatment. Future Oncol 2014; 10: $1-4$.

10. Grodski S, Brown T, Sidhu S, et al.: Increased incidence of thyroid cancer is due to increased pathologic detection. Surgery 2008; 144: 1038-43.

11. Harach HR, Franssila KO, Wasenius VM: Occult papillary carcinoma of the thyroid. A "normal" finding in Finnland. A systemic autopsy study. Cancer 1985; 56: 531-8.

12. Londero SC, Krogdahl A, Bastholt L, et al.: Papillary thyroid microcarcinoma in Denmark 1996-2008: A national study of epidemiology and clinical significance. Thyroid 2013; 23: 1159-64.

13. Bellantone R, Lombardi CP, Bossola M, et al.:Total thyroidectomy for management of benigne thyroid disease; Review of 526 cases. World J Surg 2002; 26: 1468-71.

14. Gärtner R, Dugrillon A: Vom Jodmangel zur Struma. Pathophysiologie der Jodmangelstruma. Internist 1998; 39: 566-73.

Corresponding author

Prof. Dr. med. Roland Gärtner

Medizinische Klinik IV der Ludwig Maximilians Universität

Ziemssenstr. 1, 80336 Munich, Germany

roland.gaertner@med.uni-muenchen.de

Cite this as:

Gärtner R: Nodular goiter: cautious indications for surgery. Dtsch Arztebl Int 2014; 111(10): 169-70. DOI: 10.3238/arztebl.2014.0169 